Е.Е. Шантырь

\title{
ИНТЕРПРЕТАЦИЯ ПРОФЕССИЙ И ВОПРОСЫ ПОДГОТОВКИ КАДРОВ В СФЕРЕ ПСИХОЛОГИЧЕСКИХ УСЛУГ
}

\begin{abstract}
Аннотация. Одними из наиболее актуальных проблем практической психологии в настоящее время являются вопросы подготовки специалистов и некая ориентация практической психологии на психотерапевтическую (лечебную) деятельность и медицинские термины. Первая проблема заключается в том, что специалисты в сфере психологических услуг получают образование, как в высших учебных заведениях, так и в учебных центрах различных школ и направлений, что порождает многообразие названий профессий в этой области, при этом сроки обучения принципиально разные. Мы предлагаем готовить специалистов многочисленных психологических школ и направлений, а также проводить их специализацию для работы в различных сферах человеческой деятельности только на базе высшего образования по психологии. Вторая проблема практической психологии - это медицинская терминология и отсутствие четкого теоретического разграничения в интерпретации профессиональной деятельности врачебных специальностей, связанных с проблемами психики человека и гуманитарной профессии психолога. В статье дано теоретическое обоснование принципиальных различий деятельности специалистов практической психологии и врачебных специальностей в этой области, а также показана работа практического психолога, как профессии чисто гуманитарной. В материалах работы сделан краткий исторический обзор основных направлений практической психологии и на основании этого показана сложившаяся в настоящее время ситуация в этой области. В статье представлен аналитический обзор существующих профрессий в сфере психологических услуг в России и на Украине, в том числе и с учётом Классификаторов профессий этих стран, а также показаны некоторые законодательные противоречия с точки зрения существующих проблем. Методология исследования данной работы включают в себя разработку основных подходов к подготовке кадров в срере психологических услуг, а также, на основании анализа научного материала, теоретическое обоснование принципиального отличия деятельности психологов от деятельности врачебных специальностей, связанных с проблемами психики человека.

Научная новизна данной работы заключается в представленном аналитическом обзоре существующих профессий в сфере психологических услуг в России и на Украине, в том числе и с учётом Классификаторов профессий этих стран. В статье также дано теоретическое обоснование того существующего факта, что психолог - это гуманитарная профессия, которая не включает в себя врачебное мировоззрение и лечебные манипуляции и, соответственно, не предусматривает использование медицинской терминологии. Главной целью работы практического психолога, при любой специализации, является развитие у человека его психических процессов, с челью формирования качественно новой Личности, способной решать свои проблемы в профессиональном аспекте, личной жизни, а также в отношении своего здоровья. Статья может быть интересна широкому кругу специалистов в сфере психологических услуг: научно-педагогическим сотрудникам, практическим психологам и госслужащим системы образования.
\end{abstract}

Ключевые слова: психология, практическая психология, психотерапия, подготовка кадров, интерпретация профессий, классификатор профессий, актуальные вопросы, социум, медицина, проблемы.

Review. One of most topical issues in practical psychology now is training of specialists and orientation of practical psychology at psychotherapeutic (curative) activity and medical terms. The first problem is that specialists in the field of psychological services get education both at higher educational establishments and educational centers of different psychological schools and branches of psychology. This creates a variety of professions in this area, the terms of educating 


\section{Профессиональная психология}

are fundamentally different. The authors of the present article suggest to train specialists of numerous psychological schools and directions and to conduct their practical training for work in different spheres of human activity only by higher education establishments. The second problem of practical psychology is the medical terminology and the absence of clear theoretical definitions of professional activity of medics related to the problems of mental health and psychology. The authors of the article explain theoretical grounds for fundamental distinctions of activity of specialists in practical psychology and medical specialities and demonstrate that practical psychology is an obviously humanitarian profession. The article contains a brief historical review of the basic directions of practical psychology and the current situation in this sphere. The authors also provide an analytical review of existing psychological services and associated professions in Russia and Ukraine including services mentioned in the Classifications of Professions for these two countries and point out legislative contradictions from the point of view of existing problems. The methodology of the research involves the development of the basic approaches to training of personnel in the field of psychological services and theoretical substantiation of the principal differences between psychological activity and medical activity associated with mental health based on the analysis of scientific sources. The scientific novelty of the research is caused by the fact that the authors have provided an analytical review of existing professions in the sphere of psychological services in Russia and Ukraine including professions included in the Classifications of Professions for these countries. The authors also give the theoretical justification for the fact that psychologist is a humanitarian profession that does not involve a medical world view and curative manipulations and therefore should not use medical terminology. Disregarding his major, the main objective of a practical psychologist is to encourage the development of personality and mental processes in order to form a completely new Personality capable of solving professional and personal problems and taking care of his health including mental health. The article can be of interest to a wide range of specialists in the field of psychological services, such as researchers, practical psychologists and state officials of the education system.

Keywords: problems, topical questions, psychology, practical psychology, psychotherapy, training of personnel, classification of professions, definition of professions, society, medicine.

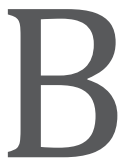

настоящее время психология, как отрасль человеческих знаний, включает в себя около 1000 различных школ и подходов, которые в свою очередь предлагают консультирование [1], как психологическую услугу, и, как минимум, 450 так называемых методов психотерапии в области практической психологии $[2 ; 3]$. Так сложилось исторически, что термин «психотерапия» был позаимствован из медицины, так как психология выросла в самостоятельную науку из философского и во многом из медицинского мировоззрения [4; 5]. Вместе с тем, психология не является отраслью медицины и ни какого отношения к терапии (лечению) не имеет.

Анализ источников литературы и ресурсов Интернета свидетельствует, что всё многообразие психологических (психотерапевтических) методов в практической психологии объединяются, в тех или иных близких по значению терминах, в три основные методологические направления:

1) Психодинамическое (психоаналитическое, глубинное) направление;

2) Когнитивно-поведенческое (бихевиоральное, бихевиористское) направление;

3) Гуманистическое, гуманитарное (феноменологическое, экзистенциально-гуманистическое) направление.
В данной статье нет, безусловно, необходимости подробно останавливаться на всех методологических направлениях практической психологии. Они достаточно широко описаны на сайтах Интернета и в доступных нам источниках литературы. Если охарактеризовать их кратко по смысловой составляющей, то теоретическое содержание их можно выразить следующим образом:

1) Психодинамическое направление практической психологии с помощью психоанализа ищет «поломку» или «ошибку» в подсознании человека, чтоб в дальнейшем на уровне сознания исправить её.

2) Когнитивно-поведенческий подход стремится сделать поведение человека адекватным, адаптивным, а его убеждения и установки рациональными в отношении себя и окружающего мира.

3) Гуманистическое (феноменологическое) направление в практической психологии занимается развитием в человеке своего «Я», поиском некоего «феномена», который есть в каждом человеке и, благодаря которому человек свободен и в полной мере может реализовывать свой жизненный потенциал.

При этом следует отметить, что целый ряд методов и школ, например, нейролингвистическое 
программирование, кататимно-имагинативную психологию, бодинамику, дианализ, психо-эмоциональный акупрессурный метод, системно-векторную психологию и многие другие, можно одновременно отнести к разным направлениям практической психологии, так как, если внимательно присмотреться, то во многих подходах можно увидеть присутствие в той или иной степени и приёмов психоанализа, и коррекции поведения, и, конечно же, гуманистических аспектов повышения уровня самооценки и развития личностных качеств собственного «Я».

В доступной нам литературе и ресурсах Интернета отсутствуют статистические данные о сравнительной эффективности различных методов и подходов, не говоря уже о целых направлениях практической психологии.

Ни одно из направлений и ни один вид психологических услуг не имеет глобальных или решающих преимуществ в работе с клиентами.

Все виды услуг, применяемых в практической психологии, дают, судя по их распространенности, примерно одинаковые результаты: различия, конечно, между ними существуют, но они минимальны и требуют, безусловно, тщательного изучения, которое весьма затруднено в условиях неоднозначности терминов и отсутствия приемлемой валидности получаемых результатов.

Необходимо, так же, отметить, что большинство психологов не являются абсолютными приверженцами какого-то одного метода или даже целого направления. Скорее, их подход - эклектический, вобравший в себя элементы из многих методов, которые они считают наиболее подходящими с учётом особенностей личности клиента и его конкретных проблем. Вместе с тем, теоретическая ориентация представителей эклектического подхода в любом случае склоняется к тому или иному методу или школе, например, скорее к психоанализу, чем к бихевиоризму. При этом они чувствуют себя вправе отбросить представления, которые сочтут не слишком полезными и заимствуют определённую методику у других школ и направлений. В настоящее время многие авторы обращают внимание на тот факт, что очень часто никакой отдельно взятый подход или метод, как в условиях индивидуальных, так и в условиях групповых психологических услуг, не приносит желаемого результата даже при решении однотипных проблем. Очевидно, поэтому интегративная психология и призывает всех специалистов использо- вать в своей работе весь арсенал известных методов и подходов [6].

Сложившаяся ситуация порождает в сфере профессиональных психологических услуг множество специалистов с самыми разными названиями своих профессий. Остановимся, вкратце, на перечне названий профессиональной принадлежности к практической психологии, которые наиболее часто встречаются в академических, научно-популярных и рекламных материалах. Прежде всего, это названия общего характера, такие как, консультант или эксперт по решению проблем семейно-брачных отношений, финансового благополучия, восстановлению отношений между людьми, развитию тех или иных личностных качеств и т.д. Далее встречаются специальности, берущее своё название от того или иного практического подхода: коуч, дианалитик, символдраматист, расстановщик, биоэнергетик, системно-векторный психоаналитик и многие другие. Самую большую группу, пожалуй, составляют специальности, в названиях которых используются медицинские термины терапевт и психотерапевт. Наиболее широко распространённые из них это гештальт-терапевт, гештальт-психотерапевт, системный семейный терапевт, кататимно-имагинативный терапевт, клиент-центрированный терапевт, бодинамический терапевт, арт-терапевт, песочный юнгианский терапевт, позитивный психотерапевт, телесно-ориентированный психотерапевт, рационально-эмотивный психотерапевт, психотерапевт Эриксоновского гипноза, нейролингвистический психотерапевт и множество других названий специальностей, где термины терапевт и психотерапевт вообще используются, как синонимы. Особенно часто это можно наблюдать в гештальт-психологии. И, наконец, название самой профессии психолог также характеризуется большим разнообразием информационных и рекламных обозначений. Довольно часто встречаются такие названия, как практический психолог, психолог-прикладник, практикующий психолог, психолог-психотерапевт, психолог-диагност, врачпсихолог, медицинский психолог, клинический психолог, психолог-педагог, психолог консультант, социальный психолог, семейный психолог, детский психолог, спортивный психолог и т.д.

Возникает уместный вопрос, на наш взгляд, а какие же названия специальностей, связанные с практической психологией, нашли своё законодательное подтверждение в Классификаторах профессий России и Украины? 


\section{Профессиональная психология}

Общероссийский классификатор профессий рабочих, должностей служащих и тарифных разрядов ОК 016-94 предусматривает в области медицины профессии врача-психиатра (участковый, детский, нарколог и подростковый), коды ОКП (общероссийский классификатор профессий) соответственно 20465, 20466, 20467,20468. При этом следует отметить, что вне классификатора профессий в России существует также и профессия врача-психотерапевта, как специальности, получаемой на основе уже существующей профессии врача-психиатра. По существующему в настоящий момент законодательству, в Российской Федерации называть себя психотерапевтом может только врач-психиатр, получивший специализацию по психотерапии в медицинском образовательном учреждении (медицинском университете или академии) и имеющий сертификат врача-психотерапевта. К медицинскому направлению относится также медицинский (клинический) психолог, код ОКП 24041. Такое образование в России можно получить в гуманитарных вузах и совсем недавно в медицинских вузах открылись факультеты клинической психологии. Медицинский психолог не является врачом и не может выписывать лекарственные средства и ставить диагнозы. Главное его отличие от психолога в том, что он может работать в медицинских учреждениях. Вне медицинского направления официальный статус имеют две профессии: психолог, код ОКП 25883 и педагог-психолог, код ОКП 25484.

В классификаторе профессий Украины ДК003:2010 среди медицинских профессий под общим кодом КП (классификатор профессий) 2221.2 имеют официальный статус такие профессии: врач-психиатр, врач-психолог, врач-психотерапевт и врач-психофизиолог. Вне медицины под кодом КП 2445.2 указаны две профессии: психолог и практический психолог. Примечательно, что практический психолог имеет право работать и в медицинских учреждениях (Приказ Министерства охраны здоровья Украины от 19.06.2008 № 10.03.67/971 «0 внесении изменений к Приказу МЗ от 23.02.2000 № 33 и согласно постановлению Кабинета Министров Украины от 14.06.2000 г. № 963»).

При сравнении в Классификаторах перечня профессий, связанных с практической психологией, мы можем отметить, что совпадает только два названия: врач-психиатр и психолог.

В украинском Классификаторе профессий в области медицины указаны четыре профессии, связан- ные с психологией. И если специальность врача-психиатра, достаточно обусловленная, и законодательно регламентирована, то профессии врача-психофизиолога и врача-психолога, как свидетельствуют законодательно утвержденные на Украине должностные инструкции, имеют одни и те же полномочия, чисто психологические, без права на диагностику заболеваний и медикаментозное лечение [7]. Если к этому добавить ещё и не медицинскую профессию практического психолога, который также имеет право работать в медицинских учреждениях, то ситуация выглядит совсем трудно объяснимой в сфере психологических услуг на Украине.

Анализируя выше сказанное, со всей очевидность можно утверждать, что на сегодняшний день существует огромное количество специальностей психологической направленности, многие из них включают в своё название чисто медицинские термины: терапия, терапевт, врач. При этом названия законодательно утверждённых специальностей в сфере психологических услуг в Классификаторах профессий России и Украины, как показано выше, существенно разнятся между собой.

Отсутствие единых научных представлений и, конечно же, законодательных актов об интерпретации, как самой практической психологии, так и её предназначении отдельно для общества и конкретно для медицины и приводит, особенно, на Украине, к различным образовательным, юридическим и методологическим курьезам в виде специальностей и должностей «врача-психолога» и «практического психолога» в медицинском учреждении. Более того, в должностной инструкции врача-психолога [7] в пункте 2.3 указано, что врачпсихолог «оказывает психологическую помощь лицам разного возраста, неспособным справиться с неблагоприятными условиями, которые сложились в их жизни». Другими словами, если, например, человек не может найти работу или у него проблемы с коммунальными службами, то он должен обращаться к врачу!? Такой подход, конечно, не соответствует основам медицины, как отрасли человеческих знаний о диагностики, лечению и профилактики болезней человека, и не способствует, а точнее, препятствует развитию и становлению практической психологии и формированию в обществе правильного отношения к специальности психолога. Таким образом, необходимо четкое обоснование теоретических основ отличительных и общих аспектов практической психологии в обществе и медицине. 


\begin{abstract}
Прежде всего, нужно согласиться с очевидным фактом, что психология не является частью медицины, а медицина не включает в себя психологию. Врач всегда имеет дело с болезнью человека (диагностика, лечение, профилактика), другими словами нет болезни, нет и профессии врача. Психолог же работает с человеком, как с личностью. В этом принципиальная разница. У врача больной человек далеко не всегда является личностью (по причине различных болезненных состояний), психолог же работает и может работать (в соответствии со спецификой своей специальности) только с человеком, как Личностью, т.е. с объектом социальной среды [8]. Что же понимать под Личностью в практической психологии?
\end{abstract}

Личность - это человек, как носитель творческого сознания.

Предлагаемое определение перекликается с определением понятия личности у К.К. Платонова: личность - человек как носитель сознания [9, с. 5657]. Мы лишь подчёркиваем, что сознание у личности творческое. Для практического психолога Личность - это всегда человек с творческим сознанием, т.е. с таким сознанием, которое наделено возможностью через чувство «Я» [10] делать осознанный выбор тех или иных действий для реализации себя в конкретной жизненной ситуации. Решение любой проблемы всегда связано с осознанным выбором нового мировоззрения и приобретением новых личностных качеств. Делая этот выбор, человек приобретает психологическую категорию Личности и задача практического психолога сделать этот выбор наиболее рациональным. Более подробно понятие «личность» рассмотрена нами в соответствующих работах $[11 ; 12]$.

Предметом деятельности врача всегда остаётся болезнь, даже если он общается с больным человеком, как личностью, что, безусловно, способствует развитию определённых личностных качеств больного человека. Предметом же деятельности психолога всегда являются психические процессы, их гармонизация и развитие, что, в конечном счёте, и приводит к формированию принципиально новой Личности человека, способной решать свои проблемы, в том числе и связанные со здоровьем.

В соответствии с интегративной психологией [6] психические процессы, как движение особого вида энергии, о которой нам пока мало, что известно, могут только эволюционировать, совершенствоваться. И проблемы человека как раз и служат движущей силой этого процесса. Решая их, человек приобретает новые, более совершенные качества психических процессов, а, следовательно, растёт, как личность. Не занимаясь, соответственно, своим развитием, человек усугубляет свои проблемы. Таким образом, медицинские термины терапия, терапевт, предусматривающие лечение болезни, здесь просто не уместны. Мы же не будем говорить человеку, который пришёл, например, на тренинг ораторского мастерства, что у него больная речь, и мы этот психический процесс будем лечить!? Как и, главное чем, можно лечить интеллектуальные, эмоциональные и другие психические процессы? Они всегда здоровы, как энергия ветра! Просто находятся на определённом уровне развития и функционального состояния. Психические процессы можно и обязательно нужно совершенствовать, гармонизировать и развивать по пути естественного эволюционирования. Это и есть сфера деятельности практического психолога, как специалиста, который реализует психологию, как науку, в социуме и в медицине. И для этого в его арсенале имеется весь набор методов и подходов современной практической психологии.

Следовательно, гештальт-терапию, например, было бы правильно называть практической гештальт-психологией, подчёркивая тем самым, что гештальт-психология имеет свои теоретические разработки, реализация которых осуществляется в рамках практической гештальт-психологии. И такой подход целесообразен, на наш взгляд, в отношении всех существующий психологических направлений.

В продолжение сказанному важно отметить, что профессию психолога можно получить только на базе высшего учебного заведения гуманитарного направления. И только на базе этого высшего образования по психологии должна быть возможна дальнейшая специализация психолога в отношении тех или иных школ и подходов, в том числе и в области медицины. При этом следует отметить, что в настоящее время существует подготовка медицинских психологов и на базе высших медицинских учебных заведениях России. Хотя, на наш взгляд, целесообразно было бы проводить там лишь специализацию психолога для работы в системе здравоохранения. Ведь основы психологии одни и те же, вне зависимости от отрасли и сферы их практической реализации, отличия заключаются лишь в конкретных условиях их применения. Зачем же в рамках медицинских вузах создавать гуманитарный вуз, в данном случае пси- 


\section{Профессиональная психология}

хологический? Это, безусловно, не простой вопрос, который требует дальнейшего изучения и законодательного урегулирования, особенно на Украине в отношении врачей-психологов, но главная проблема системы образования в области психологии заключается всё-таки в существующей на сегодняшний день другой трудно объяснимой действительности.

Во многих учебных заведениях Росси и Украины (не будем их называть, так как они достаточно широко представлены в рекламных материалах, особенно в Интернете) в течение 3-4 месяцем, максимум год можно получить сертификат определённой психологической направленности с названием профессии, обозначение которой включает в себя чисто медицинские специальности терапевт или психотерапевт, например, гештальт-терапевт, позитивный психотерапевт и т.д. При этом при поступлении в подобные учебные заведения вовсе не требуется высшее психологическое образование. А ведь, чтоб получить специальность терапевта или психотерапевта в высших медицинских учебных заведениях необходимо учиться 6 лет, а потом ещё пройти специализацию на эти профессии в течение 2-х лет. Такое положение дел, конечно же, не способствует росту авторитета профессии психолога да и правильному отношению общества к практической психологии. Особенно это касается понятия «психотерапия». В этом направлении созданы целые ассоциации психотерапевтов, специалистов, не имеющих никакого медицинского образования. Как известно, психотерапевтом в медицине можно стать, как в России, так и на Украине, только на базе специальности врача-психиатра после прохождения соответствующей специализации. В психологии же это звание можно легко получить после тех или иных краткосрочных курсов.

О возможности работать психотерапевтом в сфере психологических услуг свидетельствует и содержание Декларации по психотерапии, принятой Европейской ассоциацией психотерапии 21 октября 1990 г. в Страсбурге. Согласно этой декларации:

1) психотерапия является особой дисциплиной из области гуманитарных наук, занятие которой представляет собой свободную и независимую профессию;

2) психотерапевтическое образование требует высокого уровня теоретической и клинической подготовленности;

3) гарантированным является разнообразие психотерапевтических методов;
4) образование в области одного из психотерапевтических методов должно осуществляться интегрально; оно включает теорию, личный терапевтический опыт и практику под руководством супервизора, одновременно приобретаются широкие представления о других методах;

5) доступ к такому образованию возможен при условии широкой предварительной подготовки, в частности, в области гуманитарных и общественных наук.

Мы позволим себе поставить под сомнение некоторые положения этого документа: психотерапия является особой дисциплиной из области гуманитарных наук, занятие которой представляет собой свободную и независимую профессию (пункт 1). На каком основании психотерапию, чисто медицинскую дисциплину отнесли к гуманитарным наукам? Что специалисту в области гуманитарных и общественных наук (пункт 5) можно заниматься лечением и иметь терапевтический опыт (пункт 4)? Но, кто будет спорить с той простой истиной, которая признана и у нас и за рубежом, что человек без медицинского образования не имеет права заниматься любым видом лечебной деятельности. Так причём же тогда в чисто гуманитарной профессии термин «терапия»?

На наш взгляд, исторически не произвольно произошла подмена понятий. К тому же психотерапевт с точки зрения привлечения клиентов всем знакомый и авторитетный термин. На самом деле в психологии психотерапевт не что иное, как практический психолог, применяющий в своей работе методы развития психических процессов, которые представляют собой движение особого вида энергии. Эта энергия не может быть больной, её движение может быть не совершенным для данного индивидуума или даже искажённым по отношению к тем функциям, которые эта энергия (психические процессы) должны выполнять в сознании человека. Именно при таком искажённом течение психических процессов и возникают неврозы и психические заболевания человека. И надо сказать, что невропатолог и, особенно, врач-психиатр с помощью медикаментозного влияния, электрошока или даже хирургического влияния занимается устранением или хотя бы уменьшением последствий влияния на организм искажённого движения энергии психических процессов. Но сама энергия остаётся естественной, здоровой, как ветер, который всегда нам нужен, полезен, но при этом может причинять 
нам и вред в определённых ситуациях. Поэтому речь идёт не о том, чтоб лечить эту энергию, а о том, чтоб правильно относиться к ней и развивать в соответствии с законами мироздания, познание которых в области «энергийности» сознания человека только начинается [13; 14].

В отличие от психиатра психотерапевт в медицине занимается не психическими заболеваниями, а диагностикой, лечением и профилактикой психосоматики и патологических эмоциональных состояний, которые не позволяют человеку адекватно относиться к себе и окружающему миру. При этом эти психологические состояния (фобии, депрессии и т.д.) не позволяют человеку реализовывать себя, как личность, т.е. делать осознанный выбор действий в той или иной жизненной ситуации. Психотерапевт в таком случае назначает медикаментозное лечение, транквилизаторы, антидепрессанты и пр. с целью как бы потушить «пожар», дать человеку передышку и тем самым предоставить возможность, в том числе и с помощью психологических методов и подходов для гармонизации и развития своих психических процессов [15]. При этом вся работа психотерапевта всецело направлена на лечение болезненного патологического состояния пациента, облегчение его страданий, хотя и затрагивает, безусловно, личностные качества человека. Усилия врача всегда направлены на борьбу с болезнью или с эмоциональным патологическим состоянием. Напротив, перед психологом, в том числе и в сфере медицины, стоит задача развития личностных качеств клиента. Психологу необходимо выработать у клиента правильное отношения к медицинскому персоналу, к своей болезни, в том числе и к психосоматической патологии и, в конечном счёте, определится в тех причинах, которые порождают негативное психо-эмоциональное состояние человека. В отличие от врача практическому психологу, как раз нужны переживания и даже страдания человека, как личности, чтоб определиться, в каком направлении необходимо работать с целью развития его психических процессов. При этом важно подчеркнуть, что гармонизация и развитие психических процессов происходит исключительно под воздействием самих психических процессов клиента и психолога [13].

Важным здесь, мы бы сказали основополагающим и разграничивающим деятельность практического психолога и психотерапевта (в медицине), является то обязательное условие для работы психолога, когда психо-эмоциональное состояние человека позволяет ему оставаться Личностью. Если эмоции «бурлят» или, как говорится «зашкаливают», значит, процесс зашел слишком далеко и, прежде чем, идти к психологу необходимо восстановить себя, как Личность, что и может помочь сделать психотерапевт, в том числе с помощью медицинских препаратов.

Таким образом, подводя итоги, можно сделать следующее заключение:

1) В сфере психологических услуг населению медицинские профессии психиатр, психотерапевт и гуманитарная профессия практического психолога имеют свои абсолютно конкретные направления деятельности: врач - диагностика, лечение и профилактика болезни или патологического состояния пациента, практический психолог - развитие психических процессов клиента с целью формирования качественно новой Личности. Вместе с тем, при необходимости, специалисты этих профессий могут сотрудничать между собой в интересах конкретного человека, что, в конечном итоге, будет способствовать повышению эффективности всего комплекса медицинских и психологических услуг населению.

2) В медицине существуют две профессии, тесно связанные с психологией:

- Психиатр - занимается диагностикой, лечением и профилактикой психических заболеваний с помощью химических, физических и хирургических способов воздействия. При возможности может использовать психологические методы.

- Психотерапевт - занимается диагностикой, лечением и профилактикой патологических психоэмоциональных состояний и психосоматикой с помощью лекарственных средств и определённых психологических методов, с целью психокоррекции личностных качеств пациента.

3) В психологии также целесообразно иметь две профессии: психолог и практический психолог. При этом они должны быть взаимозаменяемыми, а их разграничение по названию связано лишь с особенностями решаемых профессиональных задач. Психолог преимущественно занимается теорией, научными исследованиями, статистикой или организацией психологических исследований или мероприятий, в то время, как практический психолог работает, в основном, непосредственно с клиентами или 


\section{Профессиональная психология}

сотрудниками предприятия. Профессия психолога или практического психолога может в дальнейшем предусматривать специализацию в области политики, производства, образования, культуры, медицины, спорта, а также в сфере деятельности институтов и учреждений общепризнанных психологических школ и направлений.

4) При всём многообразие названий профессий в сфере психологических услуг, в том числе и не входящих в Классификаторы профессий той или иной страны, деятельность специалиста в области практической психологии, при любом названии его профессии, должна обязательно базироваться на высшем психологическом образовании. При этом врачем-психологом име- ет право называться лишь специалист, имеющий высшее медицинское образование (врач) и высшее психологическое образование (психолог или практический психолог).

5) Практический психолог - гуманитарная профессия, которая не включает в себя врачебное мировоззрение и лечебные манипуляции и, соответственно, не предусматривает использование медицинской терминологии. Главной целью работы практического психолога, при любой специализации, является развитие у человека его психических процессов, с целью формирования качественно новой Личности, способной решать свои проблемы в профессиональном аспекте, личной жизни, а также в отношении своего здоровья.

\section{Список литературы:}

1. Нельсон-Джоунс Р. Теория и практика консультирования. СПб.: Питер, 2000. 464 с.

2. Марцинковская Т.Д. История психологии. М.: Академия, 2001.538 с.

3. Основные направления в психотерапии // Психологос. Энциклопедия практической психологии. (URL: http:// psychologos.ru/articles/view/osnovnye_napravleniya_v_psihoterapii).

4. Акименко М.А., Вассерман Л.И., Иовлев Б.В., Карпова Э.Б. От психоневрологии к медицинской психологии: научная система B.M. Бехтерева и В.Н. Мясищева // Медицинская психология в России: электрон. науч. журн. 2011. № 4. (URL: http://medpsy.ru/mprj/archiv_global/2011_4_9/nomer/nomer12.php).

5. Ждан А.Н. История психологии. От Античности до наших дней: учебник для вузов. 5-е изд., перераб. и доп. М.: Академический Проект, 2004. 576 с.

6. Александров А.А. Интегративная психотерапия. СПб.: Питер, 2009. 352 с.

7. Должностная инструкция - врач-психолог // Должностные инструкции Украины. (URL: http://borovik.com/index_ instruction.php?Gins=wmwi\&lang_i $\mathrm{i}=0$ ).

8. Андреева Г.М. Социальная психология. М.: Аспект Пресс, 2010. 363 с.

9. Платонов К.К. Структура и развитие личности. М.: Наука, 1986. 256 с.

10. Щербак Т.І. Розвиток образу Я у період репрезентації інтелекту особистості: Дис. ... канд. психол. наук. О., 2013. 200 с.

11. Шантырь Е.Е. Унификации базовых понятий и терминов практической психологии // Психолог. 2015. № 2. С. 99-117. (DOI: 10.7256/2409-8701.2015.2.14907. URL: http://e-notabene.ru/psp/article_14907.html).

12. Шантырь Е.Е. Унификация понятия личности, как базового термина практической психологии // Психология и соционика межличностных отношений. К., 2015. № 4. С. 50-52.

13. Фрейджер Р., Фейдимен Д. Большая книга психологии. Личность. Теории, упражнения, эксперименты. СПб.: ПраймЕврознак, 2008. 704 c.

14. Юнг К.Г. Человек. М.: АСТ-Пресс, 2007. 470 с.

15. Петрова Н.Н. Психология для медицинских специальностей. М.: Академия, 2006. 319 с.

\section{References (transliteration):}

1. Nel'son-Dzhouns R. Teoriya i praktika konsul'tirovaniya. SPb.: Piter, 2000. $464 \mathrm{s.}$

2. Martsinkovskaya T.D. Istoriya psikhologii. M.: Akademiya, 2001. 538 s.

3. Osnovnye napravleniya v psikhoterapii // Psikhologos. Entsiklopediya prakticheskoi psikhologii. (URL: http://psychologos. $\mathrm{ru} /$ articles/view/osnovnye_napravleniya_v_psihoterapii).

4. $\quad$ Akimenko M.A., Vasserman L.I., Iovlev B.V., Karpova E.B. Ot psikhonevrologii k meditsinskoi psikhologii: nauchnaya sistema V.M. Bekhtereva i V.N. Myasishcheva // Meditsinskaya psikhologiya v Rossii: elektron. nauch. zhurn. 2011. № 4. (URL: http:// medpsy.ru/mprj/archiv_global/2011_4_9/nomer/nomer12.php).

5. Zhdan A.N. Istoriya psikhologii. Ot Antichnosti do nashikh dnei: uchebnik dlya vuzov. 5-e izd., pererab.i dop. M.: Akademicheskii Proekt, 2004. 576 s.

6. Aleksandrov A.A. Integrativnaya psikhoterapiya. SPb.: Piter, 2009. $352 \mathrm{~s}$.

7. Dolzhnostnaya instruktsiya - vrach-psikholog // Dolzhnostnye instruktsii Ukrainy. (URL: http://borovik.com/index_ instruction.php?Gins=wmwi\&lang_i $=0$ ). 


\section{Психология и психотехника 9(84) • 2015}

8. Andreeva G.M. Sotsial'naya psikhologiya. M.: Aspekt Press, 2010. 363 s.

9. Platonov K.K. Struktura i razvitie lichnosti. M.: Nauka, 1986. $256 \mathrm{s.}$

10. Shcherbak T.I. Rozvitok obrazu Ya u period reprezentatsiï intelektu osobistosti. Dis. ... kand. psikhol. nauk. 0., 2013.200 s.

11. Shantyr' E.E. Unifikatsii bazovykh ponyatii i terminov prakticheskoi psikhologii // Psikholog. 2015. № 2. S. 99-117. (DOI: 10.7256/2409-8701.2015.2.14907. URL: http://e-notabene.ru/psp/article_14907.html).

12. Shantyr' E.E. Unifikatsiya ponyatiya lichnosti, kak bazovogo termina prakticheskoi psikhologii // Psikhologiya i sotsionika mezhlichnostnykh otnoshenii. K., 2015. № 4. S. 50-52.

13. Freidzher R., Feidimen D. Bol'shaya kniga psikhologii. Lichnost'. Teorii, uprazhneniya, eksperimenty. SPb.: Praim-Evroznak, 2008. $704 \mathrm{~s}$.

14. Yung K.G. Chelovek. M.: AST-Press, 2007. 470 s.

15. Petrova N.N. Psikhologiya dlya meditsinskikh spetsial'nostei. M.: Akademiya, 2006. 319 s. 